\title{
Pragmatic Method Using Blood Pressure Diaries to Assess Blood Pressure Control
}

\author{
James E. Sharman, BHMS (Hons), \\ $P h D^{1}$ \\ Leigh Blizzard, $P b D^{1}$ \\ Wojciech Kosmala, MD, $P b D^{1,2}$ \\ Mark R. Nelson, MBBS(Hons), \\ MFM, FRACGP, FAFPHM, PbD ${ }^{1}$ \\ ${ }^{1}$ Menzies Institute for Medical Research, \\ University of Tasmania, Hobart, Tasmania, \\ Australia \\ ${ }^{2}$ Wroclaw Medical University, Wroclaw, \\ Poland
}

Conflicts of interest: authors report none.

\section{CORRESPONDING AUTHOR}

James E. Sharman, BHMS (Hons), PhD Menzies Institute for Medical Research, University of Tasmania

Private Bag 23

Hobart, 7000 Australia

James.Sharman@menzies.utas.edu.au

\begin{abstract}
PURPOSE Twenty-four-hour ambulatory blood pressure (ABP) is the reference standard of blood pressure control. Home blood pressure (HBP) is superior to clinic blood pressure for assessing control, but a barrier to its use is the need for physicians to calculate average blood pressure from patient diaries. We sought to develop a quick and pragmatic method to assess blood pressure control from patients' HBP diaries.
\end{abstract}

METHODS Seven-day HBP and 24-hour ABP were measured in 286 patients with uncomplicated treated hypertension (aged $64 \pm 8$ years; 53\% female). We determined the optimal ratio of home systolic blood pressure readings above threshold $(\geq 135 \mathrm{~mm} \mathrm{Hg}$ ) for the last 10 recorded that would best predict elevated 24-hour ABP. Uncontrolled blood pressure was defined as 24-hour ABP systolic blood pressure $\geq 130 \mathrm{~mm} \mathrm{Hg}$ or 24-hour ABP daytime systolic blood pressure $\geq 135 \mathrm{~mm} \mathrm{Hg}$. Validation by corroborative evidence was tested by association with markers of end-organ disease.

RESULTS The best predictor of 24-hour ABP systolic blood pressure above treatment/target threshold was having 3 or more $(\geq 30 \%)$ of the last 10 home systolic blood pressure readings $\geq 135 \mathrm{~mm} \mathrm{Hg}$ (area under the receiver operating characteristic curve $=0.71$ ). Importantly, patients meeting this criterion had evidence of target organ disease, with significantly higher aortic stiffness, left ventricular relative wall thickness, and left atrial area, and lower left ventricular ejection fraction, compared with those who did not meet this criterion.

CONCLUSIONS To facilitate uptake of HBP monitoring, we propose that physicians can determine the percentage of the last 10 home systolic blood pressure values $\geq 135 \mathrm{~mm} \mathrm{Hg}$ for a patient and tailor management accordingly.

Ann Fam Med 2016;14:63-69. doi: 10.1370/afm.1883.

\section{INTRODUCTION}

C linic blood pressure is widely used for patient management, but the method has some limitations that may result in inaccurate assessment of true underlying blood pressure. ${ }^{1}$ Methods to assess out-of-clinic blood pressure using self-measured home blood pressure (HBP, the average blood pressure over 7 days) or 24-hour ambulatory blood pressure (ABP) have demonstrated superior prognostic utility with respect to target organ disease (eg, cardiac hypertrophy), ${ }_{1}^{2-4}$ cardiovascular events, and cardiovascular and all-cause mortality. ${ }^{5-9} \mathrm{HBP}$ has an advantage of already being in wide use, even if not in a standardized fashion. ${ }^{10,11}$ It also helps to reduce health system costs, improve adherence to therapy, and achieve better blood pressure control. ${ }^{12-17}$ Accordingly, use of HBP as a tool to help guide management of high blood pressure is advocated in many countries. ${ }^{18-25}$

A disadvantage of HBP is the requirement for manual calculation of the average of multiple values from patient diaries (eg, up to 28 recordings over 7 days) when using blood pressure devices that do not have storage memory, which currently predominate the market. If the patient has not calculated the average (which has its own reliability issue), the physician is 
unlikely to do so because of time constraints in the standard consultation. Indeed, the average number of problems managed at a clinical encounter in primary care in Australia is 1.6, and it is increasing because of aging of the population and concomitant multimorbidity. ${ }^{26}$ This rise emphasizes the need for a pragmatic alternative for physicians to assess blood pressure control from patient HBP diaries if they are to be used reliably in practice. One such method could involve quickly viewing the blood pressure diary to determine the percentage of home systolic blood pressure values above threshold $(\geq 135 \mathrm{~mm} \mathrm{Hg})^{19,23,24}$ that would have predictive value as good as that of true blood pressure control.

To the best of our knowledge, a study to determine the optimal percentage of HBP values above threshold to denote blood pressure control has never been performed and was our primary aim. We also sought to test the validity of this approach by determining associations with a variety of markers of target organ disease-aortic stiffness, left ventricular relative wall thickness, left ventricular ejection fraction, left ventricular mass index, left atrial area, and left ventricular filling pressure as estimated by the ratio of mitral inflow to mitral annular early diastolic velocity $\left(E / e^{\prime}\right)$ - in patients above the optimal percentage of values compared with those below that percentage. We hypothesized that participants with at least $20 \%$ of the last 10 home systolic blood pressure readings $\geq 135 \mathrm{~mm}$ $\mathrm{Hg}$ would be more likely to have uncontrolled blood pressure (confirmed using 24-hour ABP) and evidence of target organ disease compared with participants below the $20 \%$ cut point.

\section{METHODS}

\section{Participants}

A total of 286 patients being treated for hypertension by their primary care physicians were recruited in 3 Australian centers as part of a randomized clinical trial (Australia New Zealand Clinical Trial Registry number ACTRN12608 000041358). ${ }^{27,28}$ Recruitment was conducted through general practice clinics and community advertisement. For our analysis, we used baseline data collected before the intervention. Patient were eligible for inclusion if they were nonpregnant adults receiving antihypertensive therapy for noncomplicated essential hypertension and taking no more than 3 antihypertensive drugs, with compliance checked by the study nurse viewing each patient's medication packet(s) at the clinic visit. Exclusion criteria were as follows: severely abnormal left ventricular mass index (women $>59 \mathrm{~g} / \mathrm{m}^{2.7}$

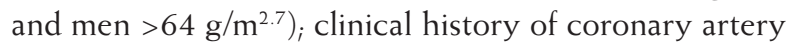
disease or renal disease; serum creatinine exceeding $1.6 \mathrm{mg} / \mathrm{dL}_{\text {; }}$ secondary causes of hypertension, uncon- trolled hypertension (clinic brachial blood pressure $>180 / 100 \mathrm{~mm} \mathrm{Hg}$ ) aortic valve stenosis; or upper limb obstructive atherosclerosis. All patients provided written informed consent, and the work was conducted in accordance with the Declaration of Helsinki.

\section{Protocol}

All patients performed HBP recording over 7 days and had measures of 24-hour ABP, aortic stiffness, left ventricular mass and function, and left atrial area assessed at the baseline examination on study enrollment. The aim was for all measures to be consecutively acquired in the shortest time frame possible (approximately 10 days). Uncontrolled blood pressure was defined as 24-hour ABP systolic blood pressure $\geq 130 \mathrm{~mm} \mathrm{Hg}$ or 24-hour ABP daytime systolic blood pressure $\geq 135$ $\mathrm{mm} \mathrm{Hg}$. We determined the optimal number of home systolic blood pressure readings $\geq 135 \mathrm{~mm} \mathrm{Hg}$ (from the last 10 recorded) to predict the presence of uncontrolled blood pressure using statistical tests of model calibration and classification. Restriction to the last 10 systolic blood pressure readings was tested because this measure would be a pragmatic, rapid, and simple way for physicians to calculate proportions from the HBP diaries. This approach is also supported by data showing that 5 days of recording (omitting the first 2 days) is a reliable estimate of usual blood pressure. ${ }^{29}$

\section{Measures}

To determine clinic blood pressure, we used an automated oscillometric device (HEM-907; OMRON Europe BV [OMCE]) to measure blood pressure in duplicate (average values presented) after patients had 5 minutes of seated rest in the clinical research laboratory.

Patients recorded 7-day HBP using a valid device with correct cuff size owned by the patient or with a machine (UA 767, A\&D Mercury) that we provided if patients did not have their own device. ${ }^{30}$ They were instructed to measure blood pressure in duplicate (1 minute apart) 3 times per day-in the morning (between $6 \mathrm{AM}$ and $10 \mathrm{AM}$ ), at noon, and in the evening (between 6 PM and 10 PM) -after 5 minutes of seated rest, with feet flat on the floor, legs uncrossed, back supported, and the arm supported at the level of the heart, as per guidelines. ${ }^{19}$ Patients were instructed to disregard the first reading and record the second reading. ${ }^{29}$ We used only the morning and evening readings for our analyses. ${ }^{19,21,23,24}$

To record 24-hour ABP, we used a validated device with correct cuff size (TM-2430, A\&D Mercury), ${ }^{31}$ with measures acquired every 30 minutes during the day (between $6 \mathrm{AM}$ and $10 \mathrm{PM}$ ) and every 60 minutes overnight (between 10 PM and $6 \mathrm{AM}$ ). 
Target organ disease was assessed from various cardiovascular measures. We measured aortic stiffness ${ }^{23,32}$ using the reference standard of tonometric carotid-to-femoral pulse wave velocity (SphygmoCor 8.0, AtCor Medical) as per expert consensus. ${ }^{33}$ Allometric left ventricular mass (indexed to $\mathrm{m}^{2.7}$ ) and left ventricular ejection fraction were measured using real time 3-dimensional echocardiography as previously described. ${ }^{34}$ Left atrial volume was assessed using 2-dimensional method of disks area-length biplane, according to American Society of Echocardiography guidelines. ${ }^{35}$ For the approximation of left ventricular filling pressure by $E / e^{\prime}$, mitral inflow velocity $(E)$ was measured by pulsed-wave Doppler at the tips of the mitral valve leaflets, and early diastolic tissue velocity $\left(e^{\prime}\right)$ was measured by pulsed wave tissue Doppler at the septal and lateral portion of the mitral annulus in the apical 4-chamber view. We used the average value of $\mathrm{e}^{\prime}$ from both sites to calculate E/e'. ${ }^{36}$

\section{Statistical Analysis}

We estimated and compared risk of the outcome (uncontrolled blood pressure) at each binary classification of the predictor (number of home SBP readings $\geq 135 \mathrm{~mm}$ $\mathrm{Hg}$ among the last 10 recorded) using $\log$ binomial regression analysis. ${ }^{37}$ To compare accuracy of prediction at different binary classifications, we calculated sensitivity and specificity ${ }^{38}$ and area under the receiver operating characteristic curve ${ }^{39}$ together with 2 alternatives to this analysis described by Pencina et $\mathrm{a}^{40}$ that have become popular in recent years for evaluating improvement in prediction: the net reclassification index and the integrated discrimination improvement. Because model calibration should be improved by adding a covariate for an additional marker of risk, we report the deviance of the fitted model. Following the approach recommended by Pepe et al ${ }_{1}^{41}$ we report the $P$ values from testing the null hypothesis about its regression coefficient. We explored multiple binary classification possibilities of the predictor (eg, $\geq 1, \geq 2, \geq 3, \geq 4 \ldots$ elevations of home SBP among the last 10 recorded) to determine the best cut points for optimal diagnostic accuracy. Only data with the best diagnostic accuracy are presented.

\section{RESULTS}

\section{Patient Characteristics}

Table 1 presents the characteristics of study patients, as well as blood pressure and markers of target organ disease related to hypertension. In the study sample, $34 \%$ of patients had controlled blood pressure based on $\mathrm{HBP}<135 \mathrm{~mm} \mathrm{Hg}$, whereas $44 \%$ had controlled blood pressure based on the average 24-hour ABP daytime systolic blood pressure $<135 \mathrm{~mm} \mathrm{Hg}$.

\section{Optimal Percentage of HBP to Predict Blood Pressure Control}

Table 2 presents the cut points that provide the optimal values of area under the curve, net reclassification index, integrated discrimination improvement, and model deviance. The cut points differed for the outcomes of mean 24-hour ABP systolic blood pressure $\geq 130 \mathrm{~mm} \mathrm{Hg}$ (for which $\geq 3$ elevations among the last 10 home recordings was the optimal cut point for all but the category-free version of net reclassification index) and 24-hour ABP daytime systolic blood pressure $\geq 135$ $\mathrm{mm} \mathrm{Hg}$ (for which $\geq 2$ elevations among the last 10 home recordings was the optimal cut point). The positive and negative predictive values of $\geq 3$ elevations were 0.85 (95\% CI, $0.78-0.91)$ and 0.56 (95\% CI 0.48-0.64), respectively, for 24-hour $\mathrm{ABP}$ systolic blood pressure $\geq 130 \mathrm{~mm} \mathrm{Hg}$, and 0.79 (95\% CI 0.72-0.86) and 0.63 (95\% CI 0.55-0.71), respectively, for 24-hour ABP daytime systolic blood pressure $\geq 135 \mathrm{~mm} \mathrm{Hg}$.

Repeating the analyses with all 14 morning and afternoon HBP readings taken over 7 days resulted in an optimal cut point of $\geq 4$ elevations for each of 24-hour $\mathrm{ABP} \geq 130 \mathrm{~mm} \mathrm{Hg}$ systolic blood pressure and 24 -hour ABP daytime systolic blood pressure $\geq 135 \mathrm{~mm}$

\section{Table 1. Clinical Characteristics of Study Participants ( $\mathrm{N}=\mathbf{2 8 6})$}

\begin{tabular}{lc}
\hline & $\begin{array}{c}\text { Value, } \\
\text { Mean (SD) } \\
\text { [range] }\end{array}$ \\
\hline Characteristic & $64(8)[24-78]$ \\
\hline Age, $y^{\text {b }}$ & $53(152)$ \\
Sex, female, \% (No.) & $29.4(4.8)$ \\
Body mass index, kg/m² & $0.95(0.48)$ \\
Waist-hip ratio & $2.4(1.4)$ \\
Antihypertensive medications (daily defined & \\
dose), No. & \\
Measures of target organ disease & $9.4(2.1)$ \\
Aortic stiffness, m/s & $0.47(0.20)$ \\
Left ventricular relative wall thickness, cm & $31.3(5.5)$ \\
Left ventricular mass index, g/m2.7 & $62(5)$ \\
Left ventricular ejection fraction, \% & $20.4(4.2)$ \\
Left atrial area, cm ${ }^{2}$ & $11.6(3.6)$ \\
Left ventricular filling pressure, E/e' & \\
Clinic blood pressure, mm Hg & $134(14)$ \\
Systolic & $78(10)$ \\
Diastolic & \\
24-hour ambulatory blood pressure, mm Hg & $133(12)$ \\
Systolic & $77(8)$ \\
Diastolic & \\
7-day home blood pressure, mm Hg & $128(13)$ \\
Systolic & $74(8)$ \\
Diastolic & \\
\hline E/e' = the ratio of mitral inflow to mitral annular early diastolic velocity. \\
a Unless otherwise noted. \\
b Eighty percent were aged 60 years or older. \\
\hline
\end{tabular}


$\mathrm{Hg}$. This cut point of $\geq 4$ elevations among the last 14 home readings is consistent with the cut point of $\geq 3$ elevations among the last 10 home readings. Additionally, the mean $\left({ }_{ \pm} \mathrm{SD}\right)$ values of 24 -hour ABP daytime systolic blood pressure and the last $10 \mathrm{HBP}$ readings were $132.7 \pm 11.1 \mathrm{~mm} \mathrm{Hg}$ and $120.4 \pm 9.8 \mathrm{~mm} \mathrm{Hg}$, respectively, for those with $<3$ elevations, and 143.4 $\pm 11.2 \mathrm{~mm} \mathrm{Hg}$ and $147.4 \pm 10.5 \mathrm{~mm} \mathrm{Hg}$, respectively, for those with $\geq 3$ elevations. Furthermore, the means of the last 14 home readings $-120.4 \pm 9.7 \mathrm{~mm} \mathrm{Hg}$ for those with $<3$ elevations, and $147.1 \pm 10.2 \mathrm{~mm} \mathrm{Hg}$ for those with $\geq 3$ elevations - were almost identical to the respective means of the last 10 readings above.

\section{Validation Analysis by Association With Target Organ Disease}

To examine whether $\geq 2$ or $\geq 3$ elevations provides the most clinically relevant cut point, Table 3 shows mean values of aortic stiffness, left ventricular relative wall thickness, left ventricular ejection fraction, left ventricular mass index, left atrial area, and E/e' for groups of patients classified by the number of elevations $(\geq 135$ $\mathrm{mm} \mathrm{Hg}$ ) in the last 10 home recordings of systolic blood pressure. On the basis of a criterion of greatest discrimination between groups, a cut point of $\geq 3$ eleva-

\begin{tabular}{|c|c|c|c|c|}
\hline \multirow{2}{*}{$\begin{array}{l}\text { Definition of Uncontrolled } \\
\text { Blood Pressure and Index }\end{array}$} & \multicolumn{2}{|c|}{ Unadjusted } & \multicolumn{2}{|c|}{ Adjusteda } \\
\hline & Cut Point & Value & Cut Point & Value \\
\hline \multicolumn{5}{|l|}{ 24-hour ABP SBP $\geq 130 \mathrm{~mm} \mathrm{Hg}$} \\
\hline$A U C^{b}$ & $\geq 3$ elevations & 0.712 & $\geq 3$ elevations & 0.722 \\
\hline$N R I^{c}$ & $\geq 3$ elevations & 0.005 & $\geq 3$ elevations & 0.004 \\
\hline Category-free NRI ${ }^{\mathrm{C}}$ & $\geq 3$ elevations & 0.010 & $\geq 2$ elevations & 0.192 \\
\hline $\mathrm{rIDl}^{\mathrm{d}}$ & $\geq 3$ elevations & 1.021 & $\geq 3$ elevations & 1.018 \\
\hline Deviance ${ }^{e}$ & $\geq 3$ elevations & 321.9 & $\geq 3$ elevations & 321.1 \\
\hline \multicolumn{5}{|l|}{$\begin{array}{l}\text { 24-hour ABP daytime SBP } \\
\geq 135 \mathrm{~mm} \mathrm{Hg}\end{array}$} \\
\hline$A U C^{b}$ & $\geq 2$ elevations & 0.717 & $\geq 2$ elevations & 0.724 \\
\hline$N R I^{c}$ & $\geq 2$ elevations & 0.072 & $\geq 2$ elevations & 0.072 \\
\hline Category-free NRI ${ }^{c}$ & $\geq 2$ elevations & 0.144 & $\geq 2$ elevations & 0.137 \\
\hline $\mathrm{rIDI}^{\mathrm{d}}$ & $\geq 2$ elevations & 1.306 & $\geq 2$ elevations & 1.237 \\
\hline Deviance ${ }^{e}$ & $\geq 2$ elevations & 331.9 & $\geq 2$ elevations & 330.3 \\
\hline
\end{tabular}

$\mathrm{ABP}=$ ambulatory blood pressure; $\mathrm{AUC}=$ area under the receiver operating characteristic curve; $\mathrm{NRI}=$ net reclassification index; $r I D I=$ relative integrated discrimination improvement; SBP = systolic blood pressure.

a For age, sex, and body mass index.

${ }^{b}$ Criterion: largest value for receiver operating characteristic curve produced from all 10 cut points ( $\geq 1$ eleva-

tions, $\geq 2$ elevations, $\geq 3$ elevations, ..., $\geq 9$ elevations, 10 elevations).

'Criterion: last classification before that producing first negative value.

${ }^{d}$ Criterion: last classification before that producing first value below unity.

e Model deviance, criterion: last classification before that producing first higher value.

Note: Elevated systolic blood pressure was defined as 24-hour ABP SBP $\geq 130 \mathrm{~mm} \mathrm{Hg}$ or 24-hour ABP daytime $\mathrm{SBP} \geq 135 \mathrm{~mm} \mathrm{Hg}$. Number of elevations was defined as number of elevations $\geq 135 \mathrm{~mm} \mathrm{Hg}$ among the last 10 recordings of morning and evening home SBP. tions was optimal for these 6 markers of end organ disease related to hypertension. This approach produces differences in mean values that are either similar to or greater than those for $\geq 2$ elevations, and only for E/e' does $\geq 3$ elevations provide a classification with a greater prognostic value. Sensitivity and specificity of the $\geq 3$ cut point were $62.1 \%$ and $80.2 \%$, respectively, for mean 24 -hour ABP systolic blood pressure $\geq 130$, and $64.6 \%$ and $77.2 \%$, respectively, for 24 -hour ABP daytime systolic blood pressure $\geq 135 \mathrm{~mm} \mathrm{Hg}$.

\section{DISCUSSION}

The use of patient HBP diaries is recommended in blood pressure management guidelines and by international expert committees. ${ }^{18-24}$ Averaging all HBP values to assess blood pressure control is impractical in busy clinical practice, however. We therefore sought to determine if it was possible to reliably determine blood pressure control and likely underlying target organ disease by quick assessment of patient HBP diaries. We found that if at least $30 \%$ of the last 10 home systolic blood pressure readings were $\geq 135 \mathrm{~mm} \mathrm{Hg}$ (the threshold for elevated blood pressure based on HBP), there was propensity toward having uncontrolled blood pressure according to 24-hour $\mathrm{ABP}$, as well as greater risk for target organ disease associated with hypertension (increased aortic stiffness, left ventricular relative wall thickness, and left atrial area, and reduced left ventricular ejection fraction). These data suggest that in patients who do not use HBP devices with storage memory, this pragmatic approach using a summary statistic is a valid aid for physicians to assess blood pressure control and help facilitate greater use of HBP monitoring in clinical practice.

Clinicians lack confidence in clinic blood pressure as a diagnostic tool because of the high prevalence of readings that conflict with out-of-clinic readings, thus potentially producing erroneous diagnosis. ${ }^{42}$ Uncertainty as to the true blood pressure based on clinic blood pressure has also been reported as a prominent reason for not intensifying therapy. ${ }^{43}$ Although ignored as a clinical tool in the United States, at least 
in the guidelines ${ }^{44} \mathrm{HBP}$ monitoring is frequently used in clinical practice in this country, ${ }^{45}$ and it has gained acceptance in Europe, Japan, and Canada. ${ }^{12,19,21-23}$ Not all patients may be committed to undertaking HBP, but several motivating factors potentially contribute to participation, including self-empowerment and engagement in their own medical management to achieve lower blood pressure. ${ }^{25}$ Indeed, a large survey of UK primary care physicians recently reported that $90 \%$ of practitioners have patients who use HBP, with about one-third of practitioners lending blood pressure monitors to patients and providing training on selfmonitoring. ${ }^{10}$ High levels of HBP use in primary care have also been reported in China. ${ }^{11}$ In Australia, general practitioners report a lack of confidence that clinic blood pressure readings provide an accurate assessment of true underlying blood pressure, and that HBP was a method being used to address clinical uncertainty around diagnosis. ${ }^{46,47}$

Despite wider use of HBP, there remains a lack of concordance with respect to clinical interpretation of HBP values. Individual patient variability in the method of recording HBP (eg, several readings on a scrap of paper with no times or dates vs highly detailed spreadsheets of blood pressure and other clinical information) contributes to this discordance. The possible practical value of our findings is that regardless of the HBP recording method the patient uses, it may still be possible to apply a quick assessment to determine the percentage of blood pressure readings above the $135-\mathrm{mm} \mathrm{Hg}$ threshold. Having said this, our findings may have been influenced by the HBP protocol that we used, and may not be generalizable to different HBP recording methods, or to patients with very high clinic blood pressure $(>180 / 100 \mathrm{~mm} \mathrm{Hg})$ as we excluded this group. Also, we did not standardize the timing of antihypertensive medication relative to HBP (other than asking patients to measure morning blood pressure before taking medication), nor attempt to control other daily life activity that may affect consistency of HBP (ie, exercise habits, food and drink intake). Nonetheless, better reproducibility and confidence in underly-

Table 3. Differences in Indicators of Target Organ Disease for Patients Not Attaining vs Attaining the Cut Point in Number of SBP Elevations During Home Blood Pressure Monitoring

\begin{tabular}{|c|c|c|c|c|}
\hline \multirow[b]{2}{*}{$\begin{array}{l}\text { Target Organ Disease } \\
\text { Indicator and Cut Point }\end{array}$} & \multicolumn{2}{|c|}{ Value, Mean (SD) } & \multirow{2}{*}{$\begin{array}{l}\text { Unadjusted } \\
\text { Difference } \\
(95 \% \mathrm{Cl})^{\mathrm{a}}\end{array}$} & \multirow{2}{*}{$\begin{array}{l}\text { Adjusted } \\
\text { Difference } \\
(95 \% \mathrm{Cl})^{a, b}\end{array}$} \\
\hline & $\begin{array}{c}\text { Did Not } \\
\text { Attain Cut Point }\end{array}$ & $\begin{array}{l}\text { Attained } \\
\text { Cut Point }\end{array}$ & & \\
\hline \multicolumn{5}{|l|}{ Aortic stiffness, m/s } \\
\hline$\geq 2$ elevations & $8.82(1.79)$ & $9.87(2.25)$ & $1.05(0.57 \text { to } 1.54)^{c}$ & $0.72(0.27 \text { to } 1.18)^{d}$ \\
\hline$\geq 3$ elevations & $8.92(1.87)$ & $9.94(2.26)$ & $1.02(0.53 \text { to } 1.51)^{c}$ & $0.71(0.25 \text { to } 1.17)^{d}$ \\
\hline \multicolumn{5}{|c|}{ Relative wall thickness in $\mathrm{cm} \times 10$} \\
\hline$\geq 2$ elevations & $4.49(0.75)$ & $4.74(0.63)$ & $0.26(0.09 \text { to } 0.04)^{d}$ & $0.26(0.09 \text { to } 0.43)^{d}$ \\
\hline$\geq 3$ elevations & $4.51(0.74)$ & $4.75(0.63)$ & $0.02(0.01 \text { to } 0.04)^{d}$ & $0.25(0.07 \text { to } 0.42)^{d}$ \\
\hline \multicolumn{5}{|c|}{ Left ventricular ejection fraction, \% } \\
\hline$\geq 2$ elevations & $62.57(5.18)$ & $60.46(5.40)$ & $-2.11(-3.48 \text { to }-0.74)^{d}$ & $-2.00(-3.43 \text { to }-0.56)^{d}$ \\
\hline$\geq 3$ elevations & $62.54(5.28)$ & $60.11(5.22)$ & $-2.43(-3.83 \text { to }-1.03)^{d}$ & $-2.34(-3.80 \text { to }-0.89)^{d}$ \\
\hline \multicolumn{5}{|l|}{ Left ventricular mass, $\mathrm{g} / \mathrm{m}^{2.7}$} \\
\hline$\geq 2$ elevations & $30.91(5.11)$ & $31.60(5.83)$ & $0.69(-0.64$ to 2.03$)$ & $0.71(-0.61$ to 2.35$)$ \\
\hline$\geq 3$ elevations & $30.71(5.17)$ & $31.99(5.83)$ & $1.28(-0.05$ to 2.61$)$ & $1.03(-0.29$ to 2.35$)$ \\
\hline \multicolumn{5}{|l|}{ Left atrial area, $\mathrm{cm}^{2}$} \\
\hline$\geq 2$ elevations & $19.91(3.78)$ & $20.72(4.57)$ & $0.80(-0.23$ to 1.84$)$ & $0.28(-0.75$ to 1.32$)$ \\
\hline$\geq 3$ elevations & $19.72(3.84)$ & $21.08(4.56)$ & $1.36(0.33 \text { to } 2.39)^{d}$ & $0.77(-0.26$ to 1.79$)$ \\
\hline$\geq 4$ elevations & $19.86(3.87)$ & $21.14(4.69)$ & $1.28(0.22 \text { to } 2.34)^{\mathrm{e}}$ & $0.76(-0.29$ to 1.80$)$ \\
\hline \multicolumn{5}{|c|}{ Left ventricular filling pressure, E/e' } \\
\hline$\geq 2$ elevations & $11.36(3.17)$ & $11.84(3.79)$ & $0.48(-0.39$ to 1.36$)$ & $0.81(-0.05$ to 1.67$)$ \\
\hline$\geq 3$ elevations & $11.28(3.22)$ & $12.04(3.87)$ & $0.76(-0.11$ to 1.63$)$ & $1.10(0.24 \text { to } 1.95)^{\mathrm{e}}$ \\
\hline$\geq 4$ elevations & $11.12(3.28)$ & $12.48(3.93)$ & $1.36(0.47 \text { to } 2.25)^{d}$ & $1.63(0.77 \text { to } 2.49)^{c}$ \\
\hline $\begin{array}{l}\text { E/e' }=\text { the ratio of mitral inflow to } \\
\text { a Difference in means between pat } \\
\text { b Adjusted for age, sex, and body } \\
\text { ' } P<.001 \text {. } \\
\text { d } P<.01 \text {. } \\
\text { e } P<.05 \text {. }\end{array}$ & $\begin{array}{l}\text { arly diastolic velocity; } \\
\text { s did not attain cut poir }\end{array}$ & = systolic blood & & \\
\hline $\begin{array}{l}\text { Note: Number of elevations } \geq 135 \\
\text { between means is similar to or hig }\end{array}$ & $\begin{array}{l}\text { he last } 10 \text { recordings } 0 \\
\geq 3 \text { elevations. }\end{array}$ & orning and even & e SBP. Results are shown for & elevations only if the difference \\
\hline
\end{tabular}


ing blood pressure is achievable when HBP is recorded by a standardized method ${ }_{1}^{48,49}$ such as that used in this current study and recommended in guidelines. ${ }^{19,21}$ Overall, the best clinical approach would be using a validated blood pressure monitor with a memory function and automated averaging, and a standard method taking into account timing of antihypertensive medications. The demonstrated association of inadequate blood pressure control with markers of target organ disease supports the validity of our approach and might suggest that the problem with a suboptimal hypotensive effect may not be limited to a recent period, but possibly is a more general phenomenon covering longer time spans. This issue could have been examined further if we had accurate detail on the duration of hypertension, but these data were not available.

In summary, we analyzed HBP diaries from patients with treated hypertension (and clinic blood pressure $\leq 180 / 100 \mathrm{~mm} \mathrm{Hg}$ ) to determine whether a summary blood pressure statistic could be derived to assess blood pressure control. Although not a perfect discriminator of true blood pressure control, we found that patients with at least $30 \%$ of the last 10 home systolic blood pressure readings $\geq 135 \mathrm{~mm} \mathrm{Hg}$ were more likely to have uncontrolled blood pressure as defined by 24 -hour ABP. Validity of the test was corroborated by a higher prevalence of hypertension-related cardiac and large artery end-organ disease in patients with at least 30\% of the last 10 home systolic blood pressure readings $\geq 135 \mathrm{~mm} \mathrm{Hg}$. Overall, this pragmatic summary statistic approach may be helpful for physicians to quickly assess data from HBP diaries in clinical practice.

\section{To read or post commentaries in response to this article, see it} online at http://www.annfammed.org/content/14/1/63.

Key words: classification; diagnosis; epidemiology; blood pressure determinations; methods; blood pressure monitoring, ambulatory; hypertension; practice-based research; primary care

Submitted June 4, 2015; submitted, revised, October 5, 2015, accepted November 3, 2015.

Funding support: J.E.S. was supported by a Career Development Award (reference 1045373), and the study was supported with a Project Grant (reference 569669) from the National Health and Medical Research Council of Australia.

\section{References}

1. Pickering TG, Hall JE, Appel LJ, et al.; Subcommittee of Professional and Public Education of the American Heart Association Council on High Blood Pressure Research. Recommendations for blood pressure measurement in humans and experimental animals: Part 1: blood pressure measurement in humans: a statement for professionals from the Subcommittee of Professional and Public Education of the American Heart Association Council on High Blood Pressure Research. Hypertension. 2005;45(1):142-161.
2. Gaborieau V, Delarche N, Gosse P. Ambulatory blood pressure monitoring versus self-measurement of blood pressure at home: correlation with target organ damage. J Hypertens. 2008;26(10):1919-1927.

3. Mulè G, Caimi G, Cottone $S$, et al. Value of home blood pressures as predictor of target organ damage in mild arterial hypertension. J Cardiovasc Risk. 2002;9(2):123-129.

4. Tsunoda S, Kawano Y, Horio T, Okuda N, Takishita S. Relationship between home blood pressure and longitudinal changes in target organ damage in treated hypertensive patients. Hypertens Res. 2002;25(2):167-173.

5. Imai $Y$, Ohkubo T, Sakuma $M$, et al. Predictive power of screening blood pressure, ambulatory blood pressure and blood pressure measured at home for overall and cardiovascular mortality: a prospective observation in a cohort from Ohasama, northern Japan. Blood Press Monit. 1996:1(3):251-254.

6. Ohkubo T, Imai Y, Tsuji I, et al. Home blood pressure measurement has a stronger predictive power for mortality than does screening blood pressure measurement: a population-based observation in Ohasama, Japan. J Hypertens. 1998;16(7):971-975.

7. Sega R, Facchetti R, Bombelli M, et al. Prognostic value of ambulatory and home blood pressures compared with office blood pressure in the general population: follow-up results from the Pressioni Arteriose Monitorate e Loro Associazioni (PAMELA) study. Circulation. 2005;111(14):1777-1783.

8. Sega R, Trocino G, Lanzarotti A, et al. Alterations of cardiac structure in patients with isolated office, ambulatory, or home hypertension: data from the general population (Pressione Arteriose Monitorate E Loro Associazioni [PAMELA] Study). Circulation. 2001;104(12): 1385-1392.

9. Mancia G, Facchetti R, Bombelli M, Grassi G, Sega R. Long-term risk of mortality associated with selective and combined elevation in office, home, and ambulatory blood pressure. Hypertension. 2006;47(5):846-853.

10. McManus RJ, Wood S, Bray EP, et al. Self-monitoring in hypertension: a web-based survey of primary care physicians. J Hum Hypertens. 2013:4:54.

11. Wang $Y$, Wang $Y, G u H$, et al. Use of home blood pressure monitoring among hypertensive adults in primary care: Minhang community survey. Blood Press Monit. 2014;19(3):140-144.

12. Imai Y, Obara T, Asamaya K, Ohkubo T. The reason why home blood pressure measurements are preferred over clinic or ambulatory blood pressure in Japan. Hypertens Res. 2013;36(8):661-672.

13. McManus RJ, Mant J, Bray EP, et al. Telemonitoring and selfmanagement in the control of hypertension (TASMINH2): a randomised controlled trial. Lancet. 2010;376(9736):163-172.

14. Kaambwa B, Bryan $S$, Jowett $S$, et al. Telemonitoring and selfmanagement in the control of hypertension (TASMINH2): a costeffectiveness analysis. Eur J Prev Cardiol. 2014;21(12):1517-1530.

15. Fukunaga $H$, Ohkubo $T$, Kobayashi $M$, et al. Cost-effectiveness of the introduction of home blood pressure measurement in patients with office hypertension. J Hypertens. 2008;26(4):685-690.

16. Edmonds D, Foerster E, Groth H, Greminger P, Siegenthaler W, Vetter W. Does self-measurement of blood pressure improve patient compliance in hypertension? J Hypertens Suppl. 1985;3(1):S31-S34.

17. Márquez-Contreras E, Martell-Claros N, Gil-Guillén V, et al.; Compliance Group of the Spanish Society of Hypertension (SEE). Efficacy of a home blood pressure monitoring programme on therapeutic compliance in hypertension: the EAPACUM-HTA study. J Hypertens. 2006;24(1):169-175.

18. Parati G, Pickering TG. Home blood-pressure monitoring: US and European consensus. Lancet. 2009;373(9667):876-878.

19. Parati G, Stergiou GS, Asmar R, et al.; ESH Working Group on Blood Pressure Monitoring. European Society of Hypertension guidelines for blood pressure monitoring at home: a summary report of the Second International Consensus Conference on Home Blood Pressure Monitoring. J Hypertens. 2008;26(8):1505-1526. 
20. Parati G, Stergiou GS, Asmar R, et al.; ESH Working Group on Blood Pressure Monitoring. European Society of Hypertension practice guidelines for home blood pressure monitoring. J Hum Hypertens. 2010;24(12):779-785.

21. Imai Y, Kario K, Shimada K, et al. The Japanese Society of Hypertension Guidelines for Self-monitoring of Blood Pressure at Home. 2nd ed. Hypertens Res. 2012;35(8):777-795.

22. Daskalopoulou SS, Khan NA, Quinn RR, et al.; Canadian Hypertension Education Program. The 2012 Canadian hypertension education program recommendations for the management of hypertension: blood pressure measurement, diagnosis, assessment of risk, and therapy. Can J Cardiol. 2012;28(3):270-287.

23. Mancia G, Fagard R, Narkiewicz K, et al.; Task Force Members. 2013 ESH/ESC Guidelines for the management of arterial hypertension: the Task Force for the Management of Arterial Hypertension of the European Society of Hypertension (ESH) and of the European Society of Cardiology (ESC). J Hypertens. 2013;31(7):1281-1357.

24. Hypertension: The Clinical Management of Primary Hypertension in Adults: Update of Clinical Guidelines 18 and 34 [Internet]. 2011 and 2013. http://www.ncbi.nlm.nih.gov/books/NBK83281/. Accessed Nov 30, 2015.

25. Sharman JE, Howes FS, Head GA, et al. Home blood pressure monitoring: Australian Expert Consensus Statement. J Hypertens. 2015; 33(9):1721-1728.

26. Britt H, Miller GC, Henderson J, et al. General Practice Activity in Australia 2012-13. Sydney, Australia: Sydney University Press; 2013. General practice series no.33.

27. Sharman JE, Marwick TH, Gilroy D, Otahal P, Abhayaratna WP, Stowasser M; Value of Central Blood Pressure for GuIDing ManagEment of Hypertension Study Investigators. Randomized trial of guiding hypertension management using central aortic blood pressure compared with best-practice care: principal findings of the BP GUIDE study. Hypertension. 2013;62(6):1138-1145.

28. Sharman JE, Marwick TH, Abhayaratna WP, Stowasser M. Rationale and design of a randomized study to determine the value of central Blood Pressure for GUIDing managEment of hypertension: the BP GUIDE study. Am Heart J. 2012;163(5):761-767.

29. Verberk WJ, Kroon AA, Kessels AG, et al. The optimal scheme of self blood pressure measurement as determined from ambulatory blood pressure recordings. J Hypertens. 2006;24(8):1541-1548.

30. Rogoza AN, Pavlova TS, Sergeeva MV. Validation of A\&D UA-767 device for the self-measurement of blood pressure. Blood Press Monit. 2000;5(4):227-231.

31. Palatini $P$, Frigo $G$, Bertolo $O$, Roman $E$, Winnicki $M$, Da Cortà R. Validation of the A\&D TM-2430 device for ambulatory blood pressure monitoring and evaluation of performance according to subjects' characteristics. Blood Press Monit. 1998;3(4):255-260.

32. Vlachopoulos C, Aznaouridis K, Stefanadis C. Prediction of cardiovascular events and all-cause mortality with arterial stiffness: a systematic review and meta-analysis. J Am Coll Cardiol. 2010;55(13): 1318-1327.

33. Laurent S, Cockcroft J, Van Bortel L, et al.; European Network for Non-invasive Investigation of Large Arteries. Expert consensus document on arterial stiffness: methodological issues and clinical applications. Eur Heart J. 2006;27(21):2588-2605.

34. Jenkins C, Bricknell K, Hanekom L, Marwick TH. Reproducibility and accuracy of echocardiographic measurements of left ventricular parameters using real-time three-dimensional echocardiography. J Am Coll Cardiol. 2004;44(4):878-886.
35. Lang RM, Bierig M, Devereux RB, et al.; Chamber Quantification Writing Group; American Society of Echocardiography's Guidelines and Standards Committee; European Association of Echocardiography. Recommendations for chamber quantification: a report from the American Society of Echocardiography's Guidelines and Standards Committee and the Chamber Quantification Writing Group, developed in conjunction with the European Association of Echocardiography, a branch of the European Society of Cardiology. J Am Soc Echocardiogr. 2005;18(12):1440-1463.

36. Ommen SR, Nishimura RA, Appleton CP, et al. Clinical utility of Doppler echocardiography and tissue Doppler imaging in the estimation of left ventricular filling pressures: a comparative simultaneous Doppler-catheterization study. Circulation. 2000;102(15):1788-1794.

37. Blizzard L, Hosmer DW. Parameter estimation and goodness-of-fit in log binomial regression. Biom J. 2006;48(1):5-22.

38. Galen ES, Gambino SR. Beyond Normality: The Predictive Value and Efficiency of Medical Diagnoses. New York, NY: John Wiley \& Sons, Inc; 1975.

39. Bamber D. The area above the ordinal dominance graph and the area below the receiver operating characteristic curve. J Math Psychol. 1975;12(4):387-415.

40. Pencina MJ, D'Agostino RB Sr, D'Agostino RB Jr, Vasan RS. Evaluating the added predictive ability of a new marker: from area under the ROC curve to reclassification and beyond. Stat Med. 2008;27(2):157-172, discussion 207-212.

41. Pepe MS, Kerr KF, Longton G, Wang Z. Testing for improvement in prediction model performance. Stat Med. 2013;32(9):1467-1482.

42. Zaninelli A, Parati G, Cricelli C, et al.; MARTE Investigators. Office and 24-h ambulatory blood pressure control by treatment in general practice: the 'Monitoraggio della pressione ARteriosa nella medicina TErritoriale' study. J Hypertens. 2010;28(5):910-917.

43. Kerr EA, Zikmund-Fisher BJ, Klamerus ML, Subramanian U, Hogan MM, Hofer TP. The role of clinical uncertainty in treatment decisions for diabetic patients with uncontrolled blood pressure. Ann Intern Med. 2008;148(10):717-727.

44. James PA, Oparil S, Carter BL, et al. 2014 evidence-based guideline for the management of high blood pressure in adults: report from the panel members appointed to the Eighth Joint National Committee (JNC 8). JAMA. 2014;311(5):507-520.

45. Ostchega Y, Berman L, Hughes JP, Chen TC, Chiappa MM. Home blood pressure monitoring and hypertension status among US adults: the National Health and Nutrition Examination Survey (NHANES), 2009-2010. Am J Hypertens. 2013;26(9):1086-1092.

46. Howes $F$, Hansen $E$, Nelson M. Management of hypertension in general practice-a qualitative needs assessment of Australian GPs. Aust Fam Physician. 2012;41(5):317-323.

47. Howes F, Hansen E, Williams D, Nelson M. Barriers to diagnosing and managing hypertension - a qualitative study in Australian general practice. Aust Fam Physician. 2010;39(7):511-516.

48. Stergiou GS, Baibas NM, Gantzarou AP, et al. Reproducibility of home, ambulatory, and clinic blood pressure: implications for the design of trials for the assessment of antihypertensive drug efficacy. Am J Hypertens. 2002;15(2 Pt 1):101-104.

49. Warren RE, Marshall T, Padfield PL, Chrubasik S. Variability of office, 24-hour ambulatory, and self-monitored blood pressure measurements. Br J Gen Pract. 2010;60(578):675-680. 